\title{
On business cycle forecasting
}

\author{
Huiwen Lai ${ }^{1 *}$ and Eric C. Y. $\mathrm{Ng}^{2}$
}

\author{
*Correspondence: afhlai@polyu. \\ edu.hk \\ ${ }^{1}$ School of Accounting and Finance, \\ Faculty of Business, Hong Kong \\ Polytechnic University, Hong Kong, \\ China \\ Full list of author information is \\ available at the end of the article
}

\begin{abstract}
We develop a recession forecasting framework using a less restrictive target variable and more flexible and inclusive specification than those used in the literature. The target variable captures the occurrence of a recession within a given future period rather than at a specific future point in time (widely used in the literature). The modeling specification combines an autoregressive Logit model capturing the autocorrelation of business cycles, a dynamic factor model encompassing many economic and financial variables, and a mixed data sampling regression incorporating common factors with mixed sampling frequencies. The model generates significantly more accurate forecasts for U.S. recessions with smaller forecast errors and stronger early signals for the turning points of business cycles than those generated by existing models.

Keywords: Recession forecasting, Business cycle, Autoregressive Logit, Dynamic factor, Mixed data sampling (MIDAS) regression
\end{abstract}

\section{Introduction}

The importance of accurately detecting turning points in the business cycle cannot be overstated. Economic agents generally make decisions based on their expectation of the future state of the economy. An accurate forecast of economic outlook is important for practitioners such as bankers and fund managers to make timely investment decisions and for policymakers such as central bankers to implement preemptive policies. If a recession can be correctly predicted, decisions can be adjusted accordingly in advance. In response to a predicted economic downturn, for example, bankers and fund managers can adopt cautious financial and investment policies such as providing fewer loans, reducing risky investments, and building up cash holdings, while central banks can implement an expansionary monetary policy.

Unfortunately, the performance of recession forecasts has been less than satisfactory to date. ${ }^{1}$ Investigating the 2001 recession in the United States, for example, Stock and Watson (2003) examine the Survey of Professional Forecasters published in the fourth quarter of 2000. They find that forecasters saw only an $11 \%$ chance of negative GDP growth in the first quarter of 2001, consistent with their optimistic growth forecast of

\footnotetext{
${ }^{1}$ The challenges for forecasting recessions are extensively documented in the literature (e.g., Filardo 1999, 2004; Fildes and Stekler 2002; Krane 2003; Lahiri and Yang 2013; Ng 2014; Ng and Wright 2013).
} 
$3.3 \%$ for that quarter; in fact, GDP growth was negative, falling by $0.6 \%$. In January 2008, 1 month after the start of the most recent recession, chairman of the Federal Reserve, Ben Bernanke testified before the House Budget Committee that despite concerns over "slowing growth," the U.S. economy remained "extraordinarily resilient," thus suggesting a recession was not on the horizon. Even after the collapse of Lehman Brothers in October 2008, the International Monetary Fund was still predicting that GDP in the United States, the Eurozone, and the world would grow by $0.1 \%, 0.2 \%$, and $2.6 \%$ in 2009 , respectively; the actual figures turned out to be $3.5 \%,-4.2 \%$, and $-2.6 \%$. Many major U.S. banks not only invested heavily in risky mortgage-backed securities at the peak of the subprime bubble around 2006, but also continued to provide bullish economic outlooks until November 2008. Most U.S. banks would have already gone bankrupt if no government bailout had been provided.

This study develops a unified framework to better forecast economic recessions than those used in the literature. The proposed model addresses two potential issues that may constrain the performance of the several existing recession forecasting models. First, most models (e.g., Estrella and Mishkin 1998; Estrella et al. 2003; Kauppi and Saikkonen 2008; Rudebusch and Williams 2009) forecast the probability of a recession occurring at a specific future point in time, for example, in the sixth month. We show that this target variable is unnecessarily restrictive and may limit the model's usefulness in capturing the onset of a recession. We thus propose an alternative target variable: a recession occurring within a specific future period, for example, within the next 6 months. This definition is less restrictive and more relevant to many economic agents' decision making. For instance, a new college graduate anxious about near-term job prospects may be concerned about the likelihood of a recession in the next few months, but less so about the exact month in which that recession will begin. Similarly, an entrepreneur developing an investment plan cares more about the state of the economy over the next year than its state at some specific month next year. Logically, before a recession starts, this less restrictive target variable allows our model to capture a more accurate and higher recession probability than the more restrictive variable widely used in the literature. In fact, a similar less restrictive target variable has been widely adopted in empirical studies predicting financial (currency or banking) crises (e.g., Berg and Coke 2004; Berg and Pattillo 1999a, b; Bussiere and Fratzscher 2002; Edison 2003; Fuertes and Kalotychou 2007; Kaminsky and Reinhart 1999). The literature often defines the probability of a currency or banking crisis within a certain period of time (say, the next 12 or 24 months) rather than at a given point in time. However, such a less restricted target variable has seldom been employed in the recession forecasting literature. ${ }^{2}$

Second, the limited forecasting performance of earlier models is also related to their inflexible model specifications and limited utilization of data. For instance, earlier

\footnotetext{
${ }^{2}$ To the best of our knowledge, Wright (2006) is the first to use this definition of the target variable in recession forecasting, although Chen et al. (2011) subsequently use the same definition. However, none of their studies explicitly acknowledge the advantages of the less restricted target variable over the conventional one. Advantages of using a less restrictive target variable section presents a numerical example to illustrate the advantages of the proposed target variable and reports that these advantages apply to all generic recession forecasting models.
} 
studies commonly apply a static Probit or Logit model that uses only a few monthly or quarterly explanatory variables to predict the probability of a recession. ${ }^{3}$ We show that our unified approach can improve forecasting performance by exploring three channels simultaneously: channel (a) - one using a more flexible Logit or Probit model specification to capture the potential autocorrelation structure of business cycles (e.g., a dynamic mechanism can be introduced by adding the lagged recession probability function as an explanatory variable); channel (b)-one incorporating the information embedded in a large number of low-frequency (i.e., monthly or quarterly) economic and financial variables; and channel (c)-one encompassing many relatively highfrequency (i.e., daily and weekly) financial and economic variables, whose information content has seldom been explored in recession forecasting because of data aggregation issues (e.g., converting weekly data into monthly data). Hence, our unified approach captures the dynamic evolution of business cycles and exploits the predictive content of a large number of variables with mixed sampling frequencies.

Recent recession forecasting studies have attempted to improve forecast precision by exploring channels (a) and (b), albeit in isolation. For example, Kauppi and Saikkonen (2008) extend the approach of Rydberg and Shephard (2003) to construct a dynamic Probit forecasting model that includes the lagged values of the binary recession dummy or underlying conditional probability of a recession. Exploring channel (a), Kauppi and Saikkonen (2008) find that dynamic models have better predictive power than static models. ${ }^{4}$ Following Bai and $\mathrm{Ng}(2006,2008)$ and Stock and Watson (2002a), Chen et al. (2011) explore channel (b), applying a static Probit model to the common factors extracted from a large set of monthly economic and financial variables. They show that dynamic common factors that contain useful information on economic downturns surpass the capacity of conventional leading indicators (e.g., the yield spread and stock prices), thereby helping improve the forecast accuracy. ${ }^{5}$ Christiansen et al. (2014) combine sentiment variables with common factors based on a large panel of macroeconomic and financial variables to predict recessions. The theme of their study, however, focuses on the predictive role of sentiment variables.

To probe channel (a) or (b), the existing recession forecasting literature relies predominantly on low-frequency predictors (quarterly or monthly data), an approach that forgoes the information content of higher-frequency data. However, the forwardlooking nature of many real-time financial variables (e.g., daily stock prices, exchange

\footnotetext{
${ }^{3}$ For example, Estrella and Mishkin's (1998) model, which includes the yield spread and stock market index; those of Estrella et al. (2003) and Rudebusch and Williams (2009), which consider only the yield spread; and that of Wright (2006), which uses the level of the federal funds rate and term spread.

${ }^{4}$ See also the earlier studies by Chauvet and Potter (2005) and Dueker (2005), which also consider different specifications of dynamic Probit models to predict U.S. recessions. Several recent studies have extended the dynamic Probit framework by evaluating the predictive ability of variables other than the yield spread. Nyberg (2010) indicates that stock returns and the foreign term spread are also significant predictors of U.S. and German recessions. Hao and $\mathrm{Ng}$ (2011) find that the combination of housing starts, real money supply, the composite index of leading indicators, and the yield spread substantially improves the performance of Canadian recession predictions. $\mathrm{Ng}$ (2012) identifies four potential recession risk factors captured by five measures as important predictors of U.S. recessions. Christiansen et al. (2014) find that consumer sentiment captured by consumer confidence and business sentiment measured by business confidence play a significant role in forecasting U.S. recessions.

${ }^{5}$ The extracted common factors have also been used to forecast both economic and financial variables in a linear regression framework (e.g., Bernanke and Boivin 2003; Ludvigson and Ng 2009; Stock and Watson 1999, 2002b). See Stock and Watson (2011) for a more complete survey of applications of dynamic factor models.
} 
rates, and interest rates) means that they may contain valuable information about the future state of the economy and thus be highly relevant for recession forecasting. To investigate channel (c), we use a mixed data sampling (MIDAS) regression to explore the predictive power of the high-frequency dynamic factors extracted from a large number of daily and weekly variables. The MIDAS approach, proposed by Ghysels et al. (2004, 2005, 2006); Ghysels et al. (2007), is a parsimonious and yet effective way to incorporate high-frequency variables in low-frequency models. The MIDAS regression model has been applied to forecast stock returns and volatility, output growth, and inflation (Andreou et al. 2010, 2011; Clements and Galvão 2008, 2009; Ghysels et al. 2005, 2006; Ghysels and Wright 2009). To the best of our knowledge, however, its usefulness in forecasting the recession probability has not been investigated to date.

This study uses the proposed target variable to explore simultaneously the three aforementioned channels to forecast U.S. recessions. Our recession forecasting model combines an autoregressive Logit specification that captures the autocorrelation of business cycles, a dynamic factor model that extracts monthly and weekly common factors from an extensive set of monthly and weekly variables, and a MIDAS regression model that incorporates common factors with mixed sampling frequencies. With this less restrictive target variable, more flexible model specifications, and the mixed-frequency factors extracted from many variables in one unified framework, our proposed model achieves better in- and out-of-sample performance in predicting U.S. recessions.

Not only does our model consistently generate more accurate recession forecasts over various time horizons (from one to 12 months), but it also sets off stronger and earlier signals for the turning points of business cycles. The out-of-sample analyses indicate that the proposed model's forecast error, as measured by the quadratic probability score (QPS) and log probability score (LPS), is $20 \%-50 \%$ lower than that of static Logit models which do not address any of these three channels. Compared with existing models that incorporate channel (a) or (b), the proposed model has a $10 \%-40 \%$ smaller forecast error. The out-of-sample results further show that the model can generate strong recession signals one to four months before the onset of past recessions. Moreover, it predicts an almost-zero recession probability in the month immediately after the end of each recession period, which sends an unambiguous signal of changes in the state of the economy.

The remainder of the paper is organized as follows. Advantages of using a less restrictive target variable section illustrates the advantages of using our proposed target variable in recession forecasting. Key methodologies in recession forecasting section reviews the key methodologies adopted in the literature. The proposed modeling framework is described in Proposed modeling framework section and the data and implementation strategy in Data and implementation strategy section. Empirical analysis section presents the empirical results and compares the forecasting performance of the proposed model with that of several existing models. This section also addresses some potential issues in implementing the model and explains why these issues may not significantly affect the robustness of our model. Conclusion section concludes.

\section{Advantages of using a less restrictive target variable}

With a few notable exceptions, existing models (e.g., Estrella and Mishkin 1998; Estrella et al. 2003; Kauppi and Saikkonen 2008) typically forecast the probability of a recession 
occurring in a specific future month (or quarter). Let the binary variable $y_{t+N}$ take the value of 1 if a recession occurs in the $N^{\text {th }}$ month (or quarter) after the current month (or quarter), termed month or quarter $t$, and 0 otherwise. We argue that this definition of a future recession may not be directly relevant to economic agents' decision making and that its restrictive nature leads us to estimate a significantly lower recession probability. These disadvantages limit a model's usefulness in capturing the onset of a recession. We thus propose a less restrictive target variable based on whether a recession will occur at any time within the next $N$ periods. More specifically, the binary variable $Y_{t+N}$ equals 1 if a recession occurs at any time within the next $N$ months and 0 otherwise. By definition, $\left(Y_{t+N}=1\right)=\left(y_{t+1}=1\right) \cup\left(y_{t+2}=1\right) \cup \ldots \cup\left(y_{t+N}=1\right)$.

Conceptually, our proposed target variable is more relevant for decision makers. When an economic agent makes a decision, the major concern is not whether a recession will occur at a specific point in time, for example, in the sixth month (i.e., $y_{t+6}=$ 1). Rather, a more relevant concern, which can be realistically addressed, is whether a recession will occur within a certain period, for example, within the next 6 months (i.e., $\left.Y_{t+6}=1\right)$. A decision taken today is more likely to reflect what will happen sometime in the future rather than at a specific point in the future. The correct prediction of the probability that $Y_{t+6}=1$ would allow an agent to adopt the necessary measures to cope with a looming recession in 6 months' time, even without knowledge of the exact month of its occurrence. For example, a fund manager who expects a forthcoming recession can gradually switch from risky stocks to safer bonds. In this context, it is important for the fund manager to know that a recession may begin within the next few months, not that it may begin in a particular month.

Our proposed target variable captures a higher probability of future recessions because of its less restrictive nature, that is, $\left(y_{t+i}=1\right) \in\left(Y_{t+N}=1\right)$ for $i=1,2$, ..., $N$. It is straightforward to show that $P\left(Y_{t+N}=1\right) \geq P\left(y_{t+i}=1\right) \forall i: P\left(Y_{t+N}=1\right)=$ $P\left[\left(y_{t+1}=1\right) \cup \ldots \cup\left(y_{t+i}=1\right) \cup \ldots \cup\left(y_{t+N}=1\right)\right] \quad=P\left(y_{t+i}=1\right)+P\left(\cup_{j \neq i}\left(y_{t+i}=1\right)\right)-P\left(\left[\cup_{j \neq}\right.\right.$ $\left.\left.i\left(y_{t+i}=1\right)\right] \cap\left[y_{t+i}=1\right]\right) \geq P\left(y_{t+i}=1\right)$. Hence, during an economic expansion period, it is easier for $Y_{t+N}$ to capture any negative shock that precedes a recession than it is for any $y_{t+i}(i=1,2, \ldots, N)$ to do so. ${ }^{6}$ For example, the most recent recession began in December 2007, approximately six months after the start of the credit crunch in the summer of 2007. Suppose another recession began three months after an observable shock similar to that of the 2007 credit crunch. Obviously, $y_{t+6}$ can capture the most recent recession but not the hypothetical one, whereas $Y_{t+6}$ can capture both.

We use a simple numerical example to show that the static Probit model using $Y_{t+N}$ has a greater chance of predicting a recession than a model with conventional target variable $y_{t+N}$. The static Probit model with $y_{t+N}$ is specified as

$$
P_{t}\left(y_{t+N}=1\right)=\Phi\left(\pi_{t}\right)
$$

where $\Phi$ is the standard normal cumulative distribution function and $\pi_{t}$ is modeled as

$$
\pi_{t}=\alpha+\beta X_{t}
$$

\footnotetext{
${ }^{6}$ While our target variable captures a larger recession probability than the conventional target variable, it does not simply capture the accumulated probabilities for the recession events from $t+1$ to $t+N$. In other words, $P\left(Y_{t+N}=1\right) \geq P\left(y_{t+i}=1\right) \forall i$, but $P\left(Y_{t+N}=1\right) \leq \sum_{i=1}^{N} P\left(y_{t+i}=1\right)$.
} 
with $X_{t}$ being the yield spread between long-term Treasury bonds (e.g., 10-year Tbonds) and short-term Treasury bills (e.g., three-month T-bills). Similarly, when we use less restrictive target variable $Y_{t+N}$, the corresponding static Probit model becomes

$$
P_{t}\left(Y_{t+N}=1\right)=\Phi\left(\pi_{t}\right) .
$$

Figure 1 compares the out-of-sample performance of these two static Probit models for $N=6$, with the yield spread as the only explanatory variable. ${ }^{7}$ The two models differ only in their choice of target dependent variable, that is, one uses $Y_{t+6}$ and the other uses $y_{t+6}$. It is clear that the model using $Y_{t+6}$ captures a higher recession probability than that using $y_{t+6}$. The model using $Y_{t+6}$ also generates strong recession signals (with a probability above 0.5 ) a few months earlier than the onsets of the recessions in July 1990 and December 2007.

In later sections, we construct Figs. 2, 3, 4, 5 and 6 by using this new target variable $Y_{t+N}$ and the information contained in a large number of economic and financial variables to model and forecast recessions. We also construct the corresponding figures (unreported) using the conventional target variable $y_{t+N}$. By comparison, $Y_{t+N}$ generates significantly higher probabilities than $y_{t+N}$ in all scenarios.

Although it may be difficult to provide a strict threshold to call for a recession, in practice an economic agent needs to see a reasonably high probability number to trigger an alarm. Using the proposed target variable will estimate a higher probability that corresponds to a more natural and less restrictive way of defining a recession falling in certain periods (rather than at a specific point of time).

\section{Key methodologies in recession forecasting}

\section{Dynamic binary response models}

One disadvantage of the static Probit model characterized in Eqs. (1) and (2) is the lack of a dynamic structure for the dependent variable. Conceptually, it makes sense to assume that the likelihood of a recession in the future depends on the current and past states of the business cycle. In the literature, two common approaches incorporate the dynamic mechanism into recession probability models (Chauvet and Potter 2005; Dueker 2005; Hao and Ng 2011; Kauppi and Saikkonen 2008; Ng 2012; Nyberg 2010). The first approach includes the lagged recession dummy variable, $y_{t-1}$, on the righthand side of Eq. (2):

$$
\pi_{t}=\alpha+\beta X_{t}+\delta y_{t-1} .
$$

The idea is that if the economy was in recession in the last period, that is, $y_{t-1}=1$, the probability of a recession in the current period also increases, that is, $\delta>0$.

However, the empirical implementation of Eq. (4) poses significant challenges. Unlike with financial variables and many economic variables available either in real time or with little delay, there is a long lag in the final confirmation of a recession's starting (or ending) date. For example, economic agents did not know for sure that the economy had been in recession since December 2007 until the declaration by the National

\footnotetext{
${ }^{7}$ See Out-of-sample performance section for the details of the out-of-sample forecasting procedures. Note that $X_{t}$ in Eq. (2) can take the lagged values of the predictors. In this example, we consider different lags of the yield spread, from one to 12 . We find that a lag of 10 results in the lowest QPS of the out-of-sample forecasts.
} 


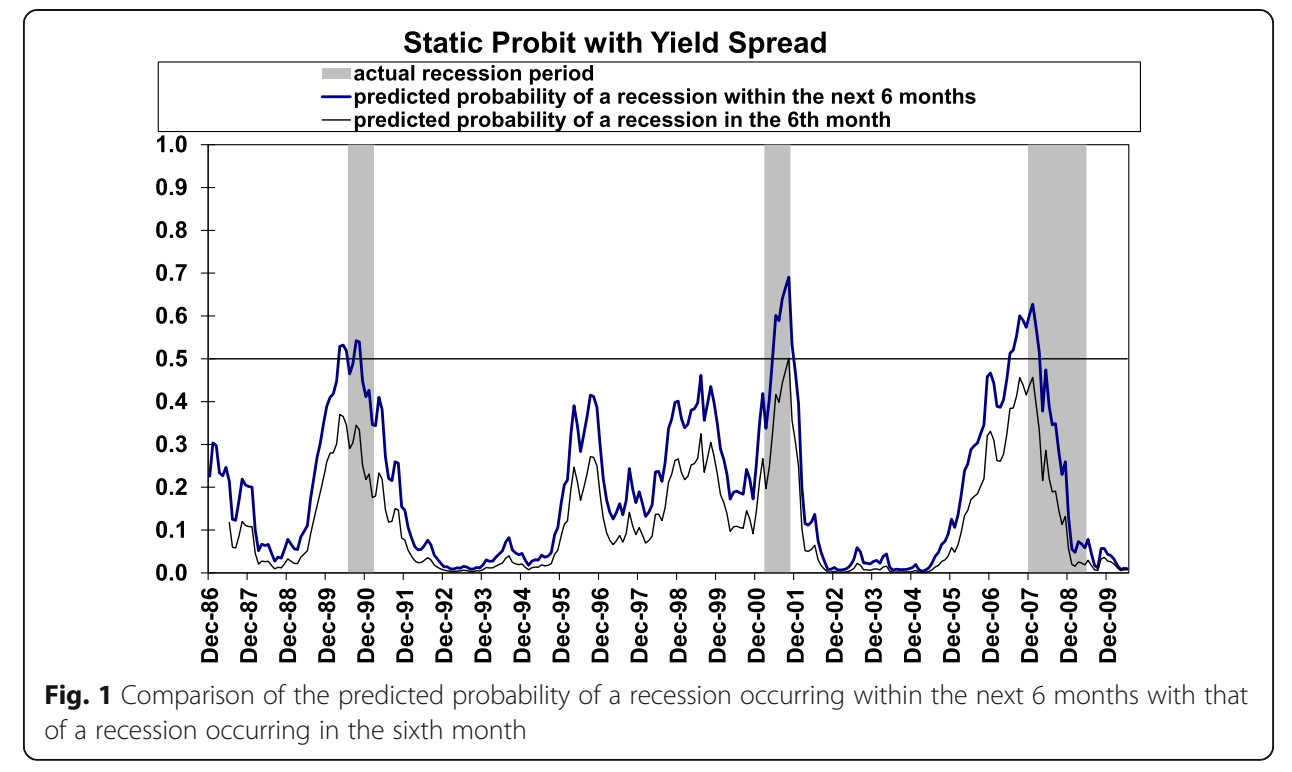

Bureau of Economic Research (NBER) in November 2008. The implication is that $y_{t-1}$ is generally unavailable for real-time forecasting. In addition, the inclusion of a lagged recession dummy can generate an artificially too-good-to-be-true result. During a recession period, the lagged recession dummy is 1 and it can dominate other explanatory variables in projecting the state of the economy, thus creating a false impression of the performance of the otherwise weak predictors in the model.

The second approach includes the lagged recession probability function on the righthand side of Eq. (2):

$$
\pi_{t}=\alpha+\beta X_{t}+\rho \pi_{t-1} .
$$

This specification affords a direct way to incorporate the potential autocorrelation of the dependent variable. It is easy to implement in practice since it is unnecessary to obtain real-time information on the recession dummy variable. Further, the lagged

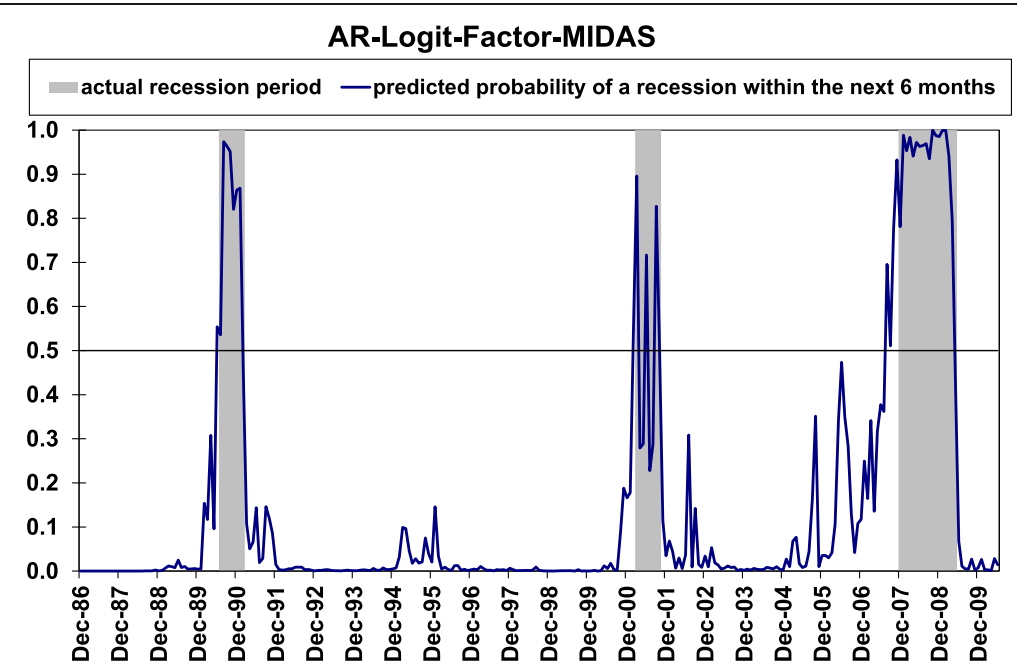

Fig. 2 Out-of-sample performance of the proposed model in predicting the last three recessions 


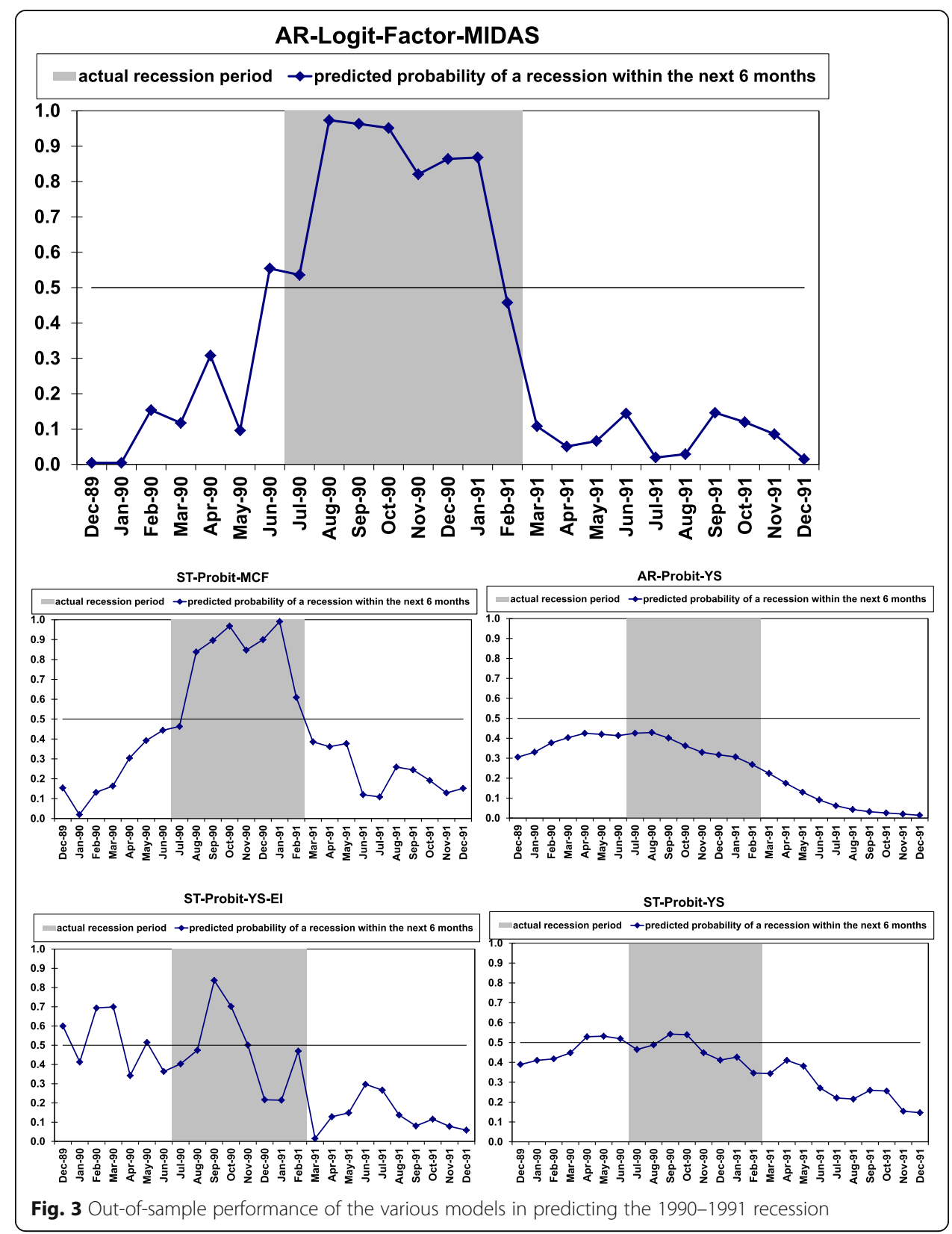

probability term allows the shocks in the other explanatory variables to be carried over to the next period, providing smoother forecasts.

As mentioned before, the inclusion of a lagged recession dummy variable is not implementable in practice. We therefore adopt the dynamic structure described in Eq. (5) to capture the autocorrelation of the state of the economy.

The dynamic factor model

Another disadvantage of the static Probit model described in Eq. (2) is that the number of variables included in the forecasting model is limited. The use of a few 


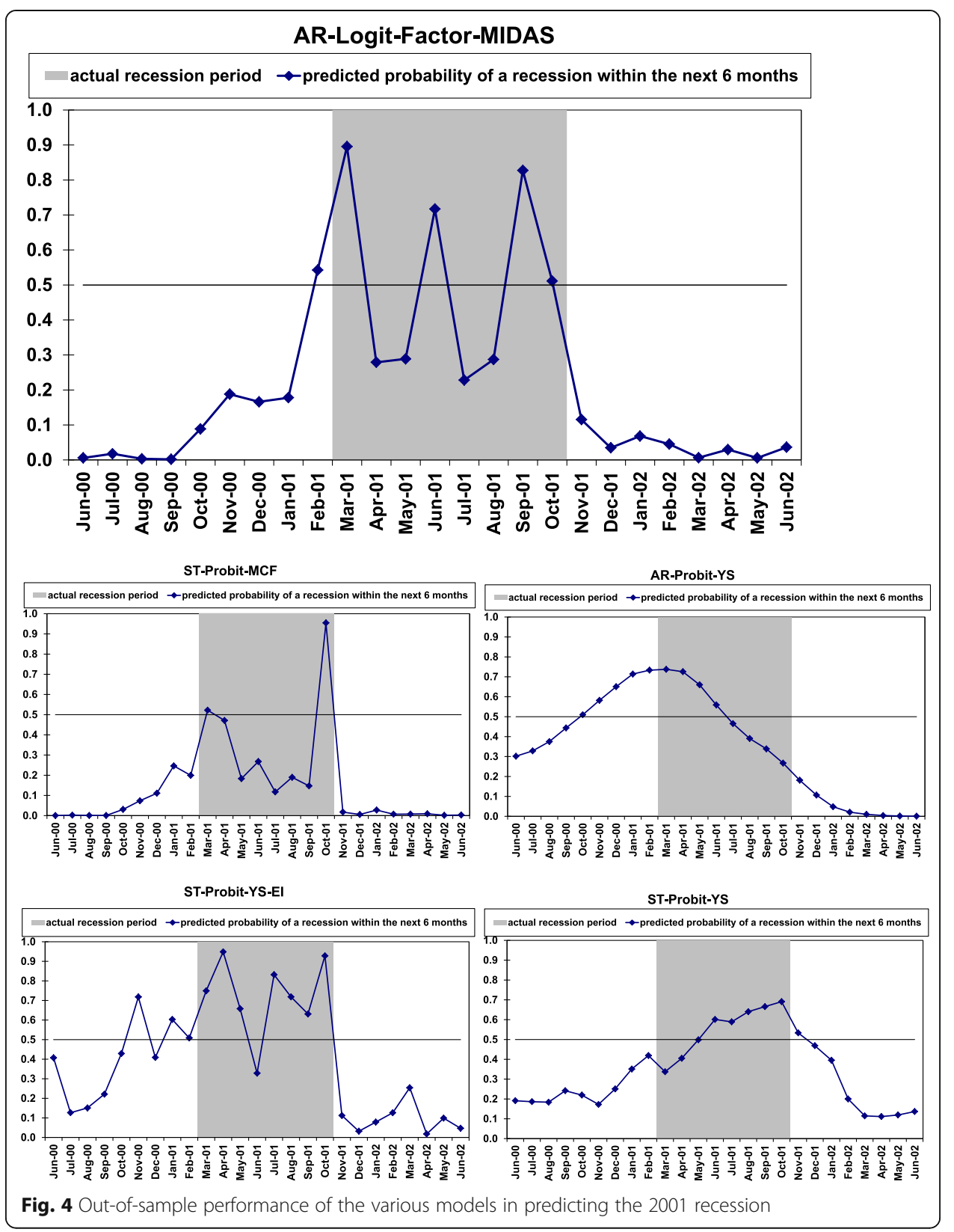

explanatory variables stems from relatively rare and short time series of recessionary periods. As a result, the inclusion of more variables, albeit well motivated, may lead to overfitting.

In a data-rich environment, the dynamic factor modeling (DFM) approach can be used to explore the predictive power of many explanatory variables. The underlying idea of DFM is that each economic variable can be decomposed into a common component and an idiosyncratic component, where the common component is a function of a few factors that drive the whole economy. A number of studies (e.g., Bai and $\mathrm{Ng}$ 2006; Forni et al. 2000, 2004, 2005; Stock and Watson 2002a, 2000b) have 


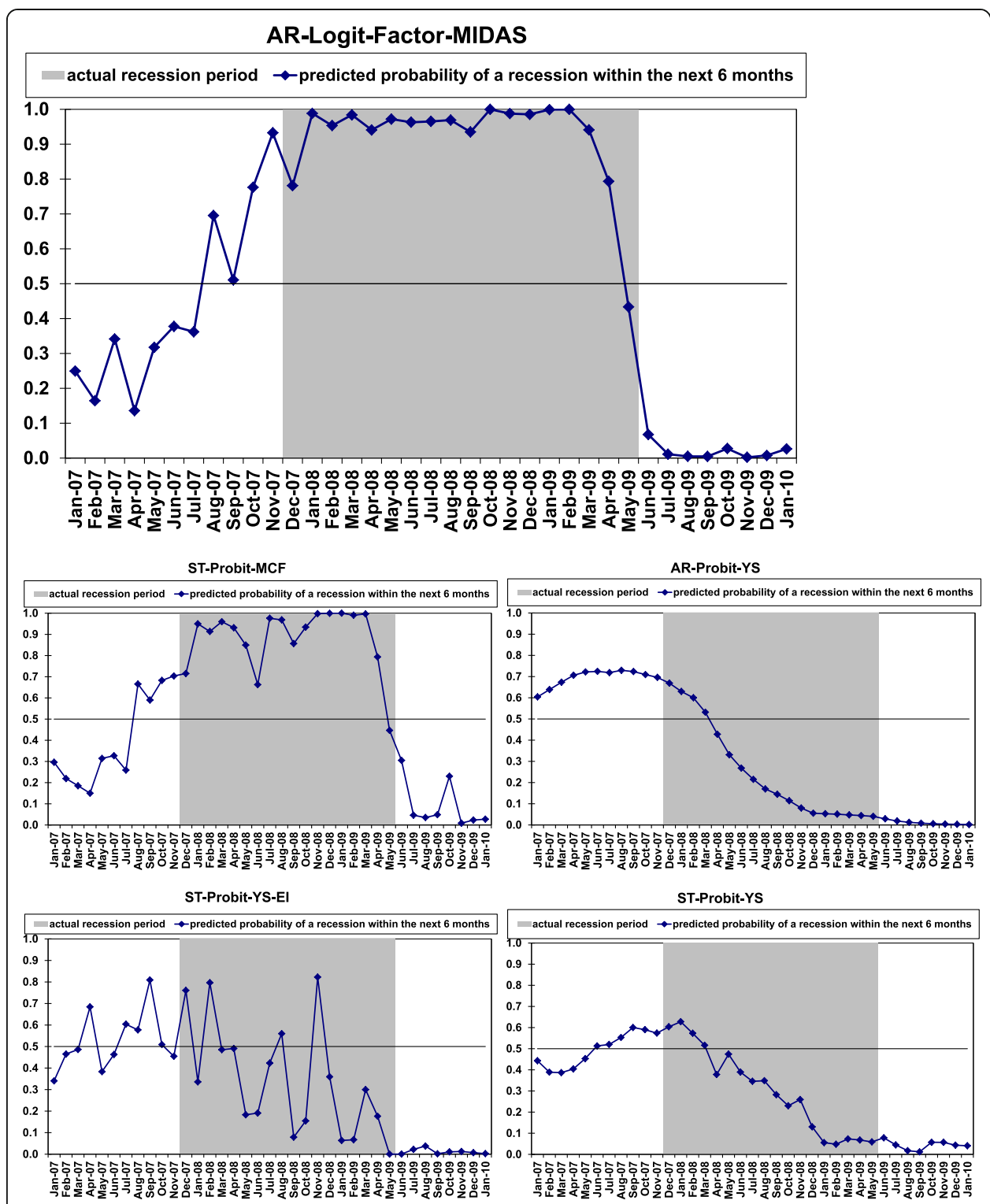

Fig. 5 Out-of-sample performance of the various models in predicting the 2007-2009 recession

demonstrated that under reasonable assumptions, principal component analysis (PCA) can be used to consistently estimate the common factors. ${ }^{8}$

Chen et al. (2011) apply DFM to recession forecasting in two steps. The first step uses PCA to extract several common factors. The second then uses these factors as predictors in the Probit model to forecast recessions. The factors are estimated from the static representation of the dynamic factor model given by

\footnotetext{
${ }^{8}$ Technically speaking, Stock and Watson (2002a, b) employ classical principal components in the time domain to estimate the static representation of their dynamic (or approximate) factor model, while Forni et al. $(2000,2004,2005)$ use dynamic principal components in the frequency domain to estimate their generalized dynamic factor model. The empirical studies of Boivin and Ng (2005), and D'Agostino and Giannone (2012) suggest that the forecasts produced using the various principal component estimators are highly collinear and that there is a negligible difference in performance among those estimators, as measured by the pseudo out-of-sample mean squared error.
} 


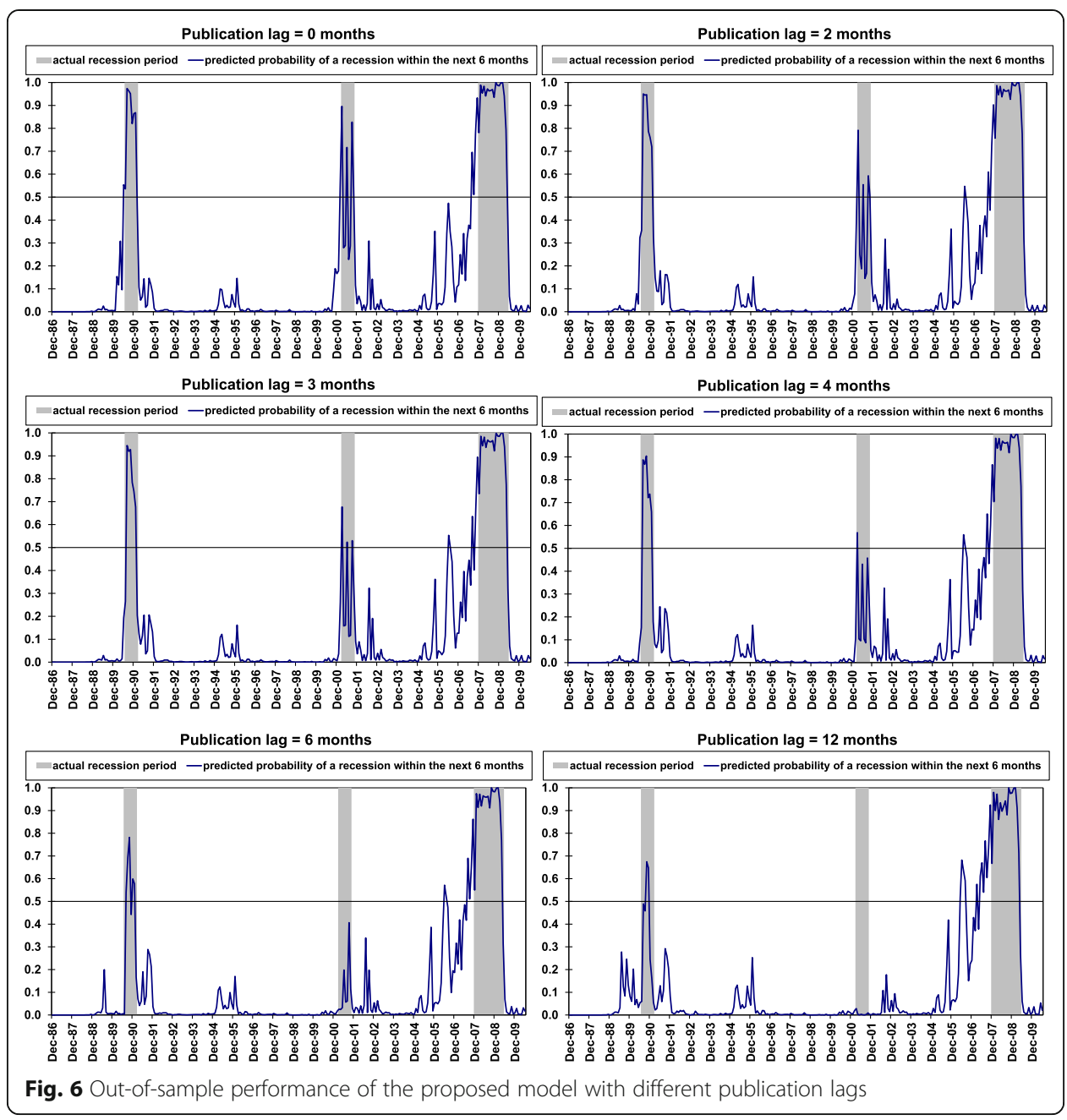

$$
X_{t}=\Lambda F_{t}+e_{t},
$$

where $e_{t}$ is an $M \times 1$ vector of idiosyncratic errors, $\Lambda$ is an $M \times r$ matrix of factor loadings, and $F_{t}$ is an $r \times 1$ vector of the common factors underlying the $M$-dimensional vector of the variables $X_{t}$. The estimated factors are then incorporated in the Probit model to predict the recession probability:

$$
\pi_{t}=\beta^{\prime} F_{t} .
$$

This approach thus allows the use of the rich information embedded in many economic and financial variables, which would otherwise be extremely difficult to incorporate in Eq. (2), for recession forecasting. Exploring 141 monthly economic variables and using the DFM framework, Chen et al. (2011) find a significant improvement in forecasting performance over previous models that use a handful of variables.

\section{The MIDAS regression model}

The static Probit or Logit model of recession forecasting uses variables with either a monthly or quarterly frequency, probably because the recession dummy variable can be defined only monthly or quarterly and most economic variables are released monthly. 
In practice, a number of high-frequency financial variables (e.g., interest rates, exchanges rates, and stock market indices) and economic variables (e.g., credits and loans, the Chicago Fed's National Financial Condition Index, and initial jobless claims) are released daily or weekly. The forward-looking nature of these variables means that they may contain valuable information about the future state of the economy and therefore could have a significant bearing on recession forecasting.

In the financial econometrics literature, Ghysels et al. $(2004,2005,2006)$ propose regressions that directly accommodate variables sampled at different frequencies. Consider a dependent variable $z_{t}$ that is available in month $t$ and an explanatory variable $x_{t}^{(m)}$ that is observed $m$ times in the same period. One approach is to regress $z_{t}$ on a history of lagged values of $x_{t-j / m}^{(m)}$, where the superscript denotes a higher sampling frequency and the exact timing lag is expressed as a fraction of the unit interval between $t-1$ and $t$. The simple MIDAS regression model can be specified as

$$
z_{t}=\gamma_{0}+\gamma_{1} B\left(L^{1 / m} ; \theta\right) x_{t}^{(m)}+\varepsilon_{t}^{(m)}
$$

where $B\left(L^{1 / m} ; \theta\right)=\sum_{i=1}^{m} b(i ; \theta) L^{(i-1) / m}$ and $L^{1 / m}$ is a lag operator such that $L^{1 / m} x_{t}^{(m)}$ $=x_{t-1 / m}^{(m)}$. The lag coefficients in $b(i ; \theta)$ of the corresponding lag operator $L^{(i-1) / m}$ are parameterized as a function of a small dimensional vector of parameters $\theta$, for example, the exponential Almon lag function (described in the next section).

This approach parsimoniously incorporates variables with mixed sampling frequencies in a model that does not suffer a significant loss of degrees of freedom. The MIDA $\mathrm{S}$ regression model has been applied to forecast stock returns and volatility, output growth, and inflation (Clements and Galvão 2008; Ghysels et al. 2005, 2006). Andreou et al. (2011) summarize MIDAS applications in different data environments. Although MIDAS has become a standard approach in economic forecasting, to the best of our knowledge, its advantages in forecasting the recession probability have not yet been investigated.

\section{Proposed modeling framework}

\section{The model}

The dependent variable $Y_{t+N}$ is a binary indicator that equals 1 if a recession occurs in any of the next $N$ months (from $t+1$ to $t+N$ ) and 0 otherwise. Conditional on information set $\Omega_{t}$ at time $t, Y_{t+N \mid t}$ has a Bernoulli distribution: $Y_{t+N} \mid \Omega_{t} \sim B\left(p_{t}\right)$. Let us define $E_{t}($.$) and P_{t}($.$) as the conditional expectation and probability, respectively,$ given $\Omega_{t}$. The conditional expectation of $Y_{t+N}$ is $E_{t}\left(Y_{t+N}\right)=P_{t}\left(Y_{t+N}=1\right)=p_{t}$. Assume that $p_{t}$ has the Logit specification ${ }^{9}$

\footnotetext{
${ }^{9}$ We employ the Logit model because of technical issues related to numerical minimization in parameter estimation. The standard normal distribution in the Probit model has a much thinner tail than the logistic distribution, even for a modestly high or low value of $\pi_{t}$. Consequently, the log of the cumulative distribution function of $\pi_{t}$ can yield infinity. The numerical instability of the Probit model worsens when high-frequency data are included since the estimation becomes more nonlinear. However, switching to the Probit model has no material effect on the performance of the proposed model. We use both the Probit and the Logit specifications to predict $P_{t}\left(Y_{t+6}=1\right)$; the in-sample and out-of-sample results show that the Logit model slightly outperforms the Probit model. The results are available upon request.
} 


$$
p_{t}=\frac{1}{1+e^{-\pi_{t}}},
$$

where $\pi_{t}$ is a function of the explanatory variables.

We propose a unified framework that simultaneously addresses the three modeling channels described in Key methodologies in recession forecasting section: (1) It uses a flexible functional form by including the lagged recession probability function in an autoregressive Logit model of recession forecasting, ${ }^{10}$ (2) it employs DFM to extract common factors from many monthly or weekly economic and financial variables, and (3) it applies the MIDAS principle to incorporate the mixed-frequency common factors in the autoregressive Logit framework. The proposed framework, denoted as the ARLogit-Factor-MIDAS model, has the following specification:

$$
\pi_{t}=\beta^{\prime} F_{t}+(1-\rho L) \sum_{k=1}^{K} \gamma_{k} B_{k}\left(L^{1 / w} ; \theta_{k}\right) f_{k, t}^{(w)}+\rho \pi_{t-1},
$$

where $F_{t}$ is the vector of the monthly common factors, $f_{k, t}^{(w)}$ is the $k^{\text {th }}$ high-frequency (weekly or daily, we apply weekly only in this study) common factor, and $k$ is the number of high-frequency common factors. Let $F_{t}^{w}$ be the vector of all the highfrequency common factors. The common factors are extracted from the static representation of the dynamic factor models, given by

$$
\begin{aligned}
& X_{\mathrm{t}}=\Lambda_{1} F_{t}+\varepsilon_{t}, \\
& X_{t}^{w}=\Lambda_{2} F_{t}^{w}+\varepsilon_{t}^{w},
\end{aligned}
$$

where $X_{t}$ and $X_{t}^{w}$ are vectors of the monthly and higher-frequency variables, respectively. Then, $B_{k}\left(L^{1 / w} ; \theta_{k}\right)=\sum_{i=1}^{w} b\left(i ; \theta_{k}\right) L^{(i-1) / w}$ and $L^{s / w} f_{k, t}^{(w)}=f_{k, t-s / w}^{(w)}$, where $t$ refers to the basic time unit (i.e., monthly), $w$ is the higher sampling frequency (in our case, $w=4$, since we incorporate weekly factors), $L^{1 / w}$ is the lag operator that operates at a higher frequency, and $b\left(i ; \theta_{k}\right)$ assigns weights to the $i^{\text {th }}$ most recent weekly observation and is parameterized by a two-parameter exponential Almon lag function (Ghysels et al. 2004, 2006) as

$$
b\left(i ; \theta_{k}\right)=\frac{\exp \left(\theta_{k, 1} i+\theta_{k, 2} i^{2}\right)}{\sum_{i=1}^{w} \exp \left(\theta_{k, 1} i+\theta_{k, 2} i^{2}\right)} .
$$

This weighting scheme allows us to obtain a temporal aggregation of higherfrequency data with a small set of parameters $\theta_{k}$. It includes a flat aggregation (i.e., the arithmetic average) as a special case when $\theta_{k, 1}=\theta_{k, 2}=0$. Most economic forecasting models generally expect a positive $\theta_{k, 1}$ and a negative $\theta_{k, 2}$, which correspond to a decaying memory pattern, with larger weights associated with more recent observations and smaller weights with more distant ones. In addition, as noted by Ghysels et al. (2007), simply adding a MIDAS term into an autoregressive structure is generally inappropriate since it generates a "seasonal" response of $\pi_{t}$ to $f_{k, t}^{(w)}$ irrespective of whether such seasonality is justified. ${ }^{11}$ We thus follow Clements and Galvão $(2008,2009)$ and

\footnotetext{
${ }^{10}$ We consider Eq. (5) instead of Eq. (4). As noted in Dynamic binary response models section, the model with the lagged recession dummy variable is difficult to implement because the recession dummy variable is not available in real time. The model with the lagged probability function, by contrast, allows a direct way to incorporate the potential autocorrelation of the dependent variable and is easier to implement in practice.
} 
introduce the MIDAS term via a common factor restriction (Hendry and Mizon 1978), multiplying it by $(1-\rho L)$, where $L$ is the lag operator at the lower frequency (i.e., monthly).

Although both the monthly and the higher-frequency factors are extracted based on a static representation of the dynamic factor models, the extracted factors may have already incorporated the lags of several underlying dynamic factors. The implication is that models with current values of the extracted factors are sufficient to capture the dynamics and interactions of both the factors and the underlying economic variables (Chen et al. 2011). ${ }^{12}$

One can intuitively see how Eq. (10) can address the three aforementioned modeling issues. First, the inclusion of $\pi_{t-1}$ as an additional explanatory variable provides a dynamic mechanism through which the probability of a recession in the future depends on the current and past states of the business cycle. Second, the incorporation of the common factors $\left(F_{t}\right.$ and $\left.F_{t}^{w}\right)$ extracted via PCA [Eqs. (11) and (12)] allows us to explore the rich information embedded in a large set of explanatory variables. Third, the MIDA $\mathrm{S}$ approach integrates weekly factors into the setting. In summary, our model nests the popular but more restrictive recession forecasting models described in Advantages of using a less restrictive target variable and Key methodologies in recession forecasting sections: (1) The static binary response model [e.g., Eq. (2)] when $\rho=0, \gamma_{k}=0$, and $F_{t}$ includes a few economic and/or financial variables, (2) the dynamic binary response model [e.g., Eq. (5)] when $\gamma_{k}=0$ and $F_{t}$ includes a few economic and/or financial variables, and (3) the static binary response model using monthly dynamic factors [e.g., Eq. (8)] when $\rho=0$ and $\gamma_{k}=0$.

\section{Estimation methodology}

We estimate the model in two stages. The first stage applies PCA to extract several monthly and weekly common factors from two large sets of monthly and weekly variables. Bai and Ng (2006) and Stock and Watson (2002a) show that under general conditions, PCA-estimated factors $\left(F_{t}, F_{t}^{w}\right)\left(\mathrm{X}_{\mathrm{t}}^{\mathrm{m}}, \mathrm{X}_{\mathrm{t}}^{\mathrm{w}}\right)$ are consistent estimators of the true latent factors of Eqs. (11) and (12). Furthermore, the feasible forecast of $\pi_{t}$, a function of the estimated factors, converges to the infeasible forecast that would be obtained if the factors and coefficients were known (Chen et al. 2011).

The second stage uses maximum likelihood estimation to estimate the parameters in Eq. (10). The maximum likelihood function has the form

$$
L(\theta)=\sum_{t=1}^{T}\left[Y_{t+N} \log \left(p_{t}(\theta)\right)+\left(1-Y_{t+N}\right) \log \left(1-p_{t}(\theta)\right)\right]
$$

where $\theta=\left[\beta^{\prime} \rho \gamma_{k}^{\prime} \theta_{k}^{\prime}\right]$ is the set of parameter vectors to be estimated. Because the model has a lagged probability function term on the right-hand side, we need to choose the initial value of $\pi_{0}$. We follow Kauppi and Saikkonen (2008) and set $\pi_{0}$ equal to the unconditional mean of $\pi_{t}$ :

\footnotetext{
${ }^{11} \mathrm{We}$ conduct standard seasonality tests and find that $f_{k, t}^{(w)}$ does not display a seasonal pattern.

${ }^{12}$ Stock and Watson (2002b) find that, in most cases, the performance of models without lagged factors compares with or even improves on that of models with lagged factors.
} 


$$
\pi_{0}=\frac{1}{T(1-\rho)} \sum_{t=1}^{T}\left(\beta^{\prime} F_{t}+(1-\rho L) \sum_{k=1}^{K} \gamma_{k} B_{k}\left(L^{1 / w} ; \theta_{k}\right) f_{k, t}^{(w)}\right) .
$$

\section{Data and implementation strategy \\ Data}

The Business Cycle Dating Committee of the NBER announces the beginning and end dates of U.S. recessions recorded in months and quarters. We use monthly NBER data on the recession dates to construct the time series of both the proposed target variable, $Y_{t+N}$, and the conventional target variable, $y_{t+N}$, for different values of $N$, from one to 12 months.

We use two sets of data with different frequencies. The first set comprises 141 monthly variables sampled from January 1964 to June 2010. This dataset is extended on the basis of the work of Chen et al. (2011). ${ }^{13}$ The monthly data are used to extract the monthly common factors, $F_{t}$ and $\mathrm{F}_{\mathrm{t}}^{\mathrm{m}}$. The monthly economic and financial variables can be grouped into 14 main categories: real output; real income; employment and hours; real retail, manufacturing, and trade sales; consumption; housing starts and sales; real inventories and inventory-sale ratios; orders and unfilled orders; stock prices; exchange rates; interest rates; money and credits, and price indices; average hourly earnings; and miscellaneous. ${ }^{14}$ Following standard practice, we transform all the variables using either logarithms or first differences and screen outliers. All the transformed variables are then standardized to ensure a sample mean of 0 and a sample variance of 1 .

The second set of data includes both weekly and daily variables obtained from various sources, including the Federal Reserve Economic Data of the Federal Reserve Bank of St. Louis, the Data Download Program of the Board of Governors of the Federal Reserve System, the Bloomberg database, and Yahoo Finance. The sampling period is from January 1973 to June 2010. We aggregate the daily variables to a weekly frequency and combine them with the other weekly variables. ${ }^{15}$ The weekly dataset comprises 118 variables classified into six main categories: yields on T-bonds and T-bills, state and local government bonds, and corporate bonds; money market interest rates; bank credits and loans and financial condition indices; stock market indices; exchange rates; and unemployment-related statistics. ${ }^{16}$ Similarly, the weekly data are used to extract the weekly common factors, $F_{t}^{w} \cdot{ }^{17}$ We also perform transformations similar to those outlined above and standardize all the variables before PCA extraction.

\footnotetext{
${ }^{13}$ We thank Azhar Iqbal for providing us with the updated data.

${ }^{14}$ The full list of variables and related transformations are available upon request.

${ }^{15}$ The daily variables contain purely financial data such as interest rates on T-bills/T-bonds, money market interest rates, stock market indices, and exchange rates and the weekly variables include economic indicators such as jobless claims statistics, the insured unemployment rate, bank credits and loans, financial conditions, and corporate bond yields. A combined dataset with both daily and weekly variables therefore captures more categories and provides a more complete picture of the economic conditions.

${ }^{16}$ The full list of variables is available upon request.

${ }^{17}$ Alternatively, we use the original dataset of daily variables to extract the daily common factors and then include these with the weekly and monthly common factors in Eq. (10). The model with only the monthly and weekly common factors exhibits better out-of-sample forecasting performance (in terms of the QPS or LPS) than all three types of common factors or that with only the monthly and daily common factors.
} 


\section{Implementation strategy}

As previously noted, the proposed model combines the three modeling channels described in Key methodologies in recession forecasting section into a unified framework. We estimate and evaluate the forecasting performance of the AR-LogitFactor-MIDAS model relative to that of several alternative models in the literature, which address either none or one of the three foregoing channels. The alternative models include (1) the static Probit model of Estrella and Mishkin (1998) with the yield spread as the explanatory variable (ST-Probit-YS), (2) the static Probit model of Estrella and Mishkin (1998) with the yield spread and stock market index return as the explanatory variables (ST-Probit-YS-EI), (3) the autoregressive Probit model of Kauppi and Saikkonen (2008) with the lagged probability function and yield spread as the explanatory variables (AR-Probit-YS), and (4) the static Probit model of Chen et al. (2011) with the dynamic factors as the explanatory variables (ST-Probit-MCF).

For each forecast horizon $N(=1,2,3, \ldots, 12)$, we evaluate the ability of each model to forecast the probability of a recession occurring within the next $N$ months, that is, $P_{t}\left(Y_{t+N}=1\right) .{ }^{18}$ The QPS, LPS, and area under the receiver operating characteristic (ROC) curve (AUC hereafter) are used as the evaluation statistics. The first two measures are regarded as proper scoring rules (Lahiri and Yang 2013), while the third measure was proposed by Berge and Jordà (2011) to assess the overall ability to classify recession and non-recession signals. The QPS and LPS are defined, respectively as

$$
Q P S=\frac{1}{T} \sum_{t=1}^{T} 2\left(\widehat{p}_{t}-Y_{t+N}\right)^{2},
$$

and

$$
L P S=-1 / T \sum_{t=1}^{T}\left[\left(1-Y_{t+N}\right) \ln \left(1-\widehat{p}_{t}\right)+Y_{t+N} \ln \left(\widehat{p}_{t}\right)\right],
$$

where $\widehat{p}_{t}$ is the fitted probability of a recession occurring in any of the next $N$ months (from $t+1$ to $t+N$ ) and $T$ is the number of in- or out-of-sample forecasts.

To construct the AUC, we follow Berge and Jordà (2011) by first defining

$$
T P(c)=P\left[\widehat{p}_{t} \geq c \mid Y_{t+N}=1\right],
$$

and

$$
F P(c)=P\left[\widehat{p}_{t} \geq c \mid Y_{t+N}=0\right],
$$

where $T P(c)$ is the true positive rate (or sensitivity) and $F P(c)$ is the false positive rate (or 1 - specificity). The $R O C$ curve plots the entire set of possible combinations of $T P(c)$ and $F P(c)$ for $c \in(-\infty, \infty)$. The $R O C$ curve is generally represented by the Cartesian convention $\{R O C(r), r\}_{r=0}$, where $R O C(r)=T P(c)$ and $r=F P(c)$. The overall classification ability is measured by the AUC:

$$
A U C=\int_{0}^{1} R O C(r) d r
$$

where $A U C \in[0.5,1]$. A model with $A U C=1$ means that it classifies recession signals

\footnotetext{
${ }^{18}$ To conserve space, we report only the in- and out-of-sample results for $N=1,3,6,9,12$. The conclusions for both are consistent for the other values of $N$.
} 
perfectly (with a $100 \%$ true positive rate and a 0 false positive rate). On the contrary, a model with $A U C=0.5$ is no different from a coin-toss classifier.

As noted in The model section, the current values of the extracted factors suffice to incorporate the dynamic interactions between the factors and underlying variables. Therefore, both AR-Logit-Factor-MIDAS and ST-Probit-MCF use only the current values of the extracted factors in both the in- and the out-of-sample estimations. Regarding the number of monthly common factors used for the estimation, we follow Chen et al. (2011) in choosing the first eight factors sorted by descending order of eigenvalues. These eight factors account for about $60 \%$ of the variation in the data. For the number of weekly common factors, we select the first two weekly factors with the highest eigenvalues. This method is motivated by two practical considerations. First, the set of monthly variables already comprises some of the aggregated high-frequency variables. Therefore, the incremental information content of additional weekly factors may be less than that of the monthly factors. Second, the MIDAS terms are highly nonlinear and thus impose a considerable computational burden on the maximum likelihood estimation. Nonetheless, we find that the introduction of additional weekly factors does not markedly improve forecasting performance. ${ }^{19}$

For the other three models, the parameter estimation considers different lags of the explanatory variables. We use the QPS as an evaluation criterion to choose the optimal lags of these variables. For the in- and out-of-sample analyses, we consider different lags, from one to 12, and search for the optimal lags (i.e., those that generate the lowest QPS for the entire sample period).

\section{Empirical analysis}

\section{In-sample performance}

We estimate each model using data from January 1973 to June 2010. Table 1 presents the QPS and LPS of the in-sample estimates over different forecasting horizons $(N=1$, $3,6,9,12)$. To facilitate comparison across models, we choose ST-Probit-YS as the benchmark model and normalize its QPS and LPS to 1 . The corresponding scores for the other models shown in Table 1 represent their original scores relative to those of the benchmark model. We also conduct the Diebold-Mariano test to examine whether the forecasts of the model being tested are significantly different from those of the benchmark model (Diebold and Mariano 1995). ${ }^{20}$ Clearly, AR-Logit-Factor-MIDAS, which incorporates the three aforementioned channels simultaneously, outperforms the alternative models. AR-Logit-Factor-MIDAS exhibits a substantial reduction of $40 \%-60 \%$ in the forecast error (as measured by either the QPS or the LPS) relative to the static models that consider none of the channels (ST-Probit-YS-EI or ST-Probit-YS). Compared with the models that incorporate channel (a) or (b) (AR-Probit-YS or ST-Probit-MCF), AR-Logit-Factor-MIDAS also reduces the forecast error by $10 \%-50 \%$. The Diebold-Mariano test further suggests a significant difference in the forecast

\footnotetext{
${ }^{19}$ Considering different combinations of the number of weekly common factors with the eight monthly common factors, we find that the combination of the first two weekly factors and eight monthly common factors (in descending order of eigenvalues) yields the lowest QPS and LPS in the out-of-sample analysis. ${ }^{20}$ In the table, the numbers in parentheses are the $p$-values of the Diebold-Mariano test with the null hypothesis of equal forecast accuracy between the model being tested and benchmark model (ST-Probit-YS).
} 
accuracy between AR-Logit-Factor-MIDAS and the benchmark model. This finding is consistent with the relatively small forecast error of AR-Logit-Factor-MIDAS.

Table 2 summarizes the AUC generated by each model. ${ }^{21}$ AR-Logit-Factor-MIDAS also outperforms the other models in the overall ability to classify recession and nonrecession signals. It consistently generates a larger percentage of correct recession signals (true positive rate) and fewer false alarms (false positive rate) than the other models. In particular, AR-Logit-Factor-MIDAS shows a moderate improvement in the AUC compared with ST-Probit-YS, ST-Probit-YS-EI, and AR-Probit-YS.

\section{Out-of-sample performance}

The in-sample results do not necessarily imply the same out-of-sample performance. To evaluate further the proposed model relative to the alternative models, we implement the standard out-of-sample estimation procedure in the literature (e.g., Estrella and Mishkin 1998). The out-of-sample forecasts are obtained from the moving sample periods of the first sample window between January 1973 and December 1986 and the last sample window between January 1973 and June 2010. We use the first sample window to estimate the parameters and make the nextperiod forecasts for the recession probability. We then extend the sample period by 1 month and repeat the estimation and forecasting procedures until the last sample window is used. ${ }^{22}$

Table 3 reports the out-of-sample estimation results gauged by the QPS and LPS. Overall, AR-Logit-Factor-MIDAS still dominates the other models by generating a smaller forecast error over all the forecast horizons. The QPS and LPS of AR-LogitFactor-MIDAS are $20 \%-50 \%$ and $10 \%-40 \%$, respectively, less than those of the models that address none of the three channels or channel (a) only (ST-Probit-YS-EI, STProbit-YS, and AR-Probit-YS). Relative to the model that addresses channel (b) only (ST-Probit-MCF), the outperformance of AR-Logit-Factor-MIDAS is more pronounced for short horizons ranging from one to six months. The forecast error (as measured by either the QPS or the LPS) of AR-Logit-Factor-MIDAS is $10 \%-20 \%$ less than that of ST-Probit-MCF. As in the in-sample analysis, the Diebold-Mariano test in the out-ofsample analysis suggests a significant difference in the forecast accuracy between ARLogit-Factor-MIDAS and the benchmark model.

Table 4 indicates that AR-Logit-Factor-MIDAS also outperforms the other models in terms of the overall ability to classify recession and non-recession signals. The improvement in the AUC from AR-Logit-Factor-MIDAS is more noticeable compared with the models that address none of the three channels or channel (a) only (ST-Probit-YS-EI, ST-Probit-YS, and AR-Probit-YS).

Overall, the above results suggest that the proposed model generates relatively more accurate recession forecasts with smaller forecast errors. We then examine whether the model can accurately predict the turning points of business cycles. A good forecasting model can flag a strong recession signal (with high predicted probability) before the

\footnotetext{
${ }^{21}$ We also conduct the Hanley-McNeil test to examine whether the classification ability of the model being tested is significant from the random coin-toss classifier (Hanley and McNeil 1982). In Tables 2 and 4, the numbers in parentheses are the $p$-values of the null hypothesis of no classification ability $\left(\mathrm{H}_{0}: \mathrm{AUC}=0.5\right)$. All the models are found to be statistically significant from the random coin-toss classifier.

${ }^{22}$ To obtain the data for the common factors in the moving sample windows, we follow the procedures of Chen et al. (2011).
} 
Table 1 In-sample estimation results: relative QPS and LPS

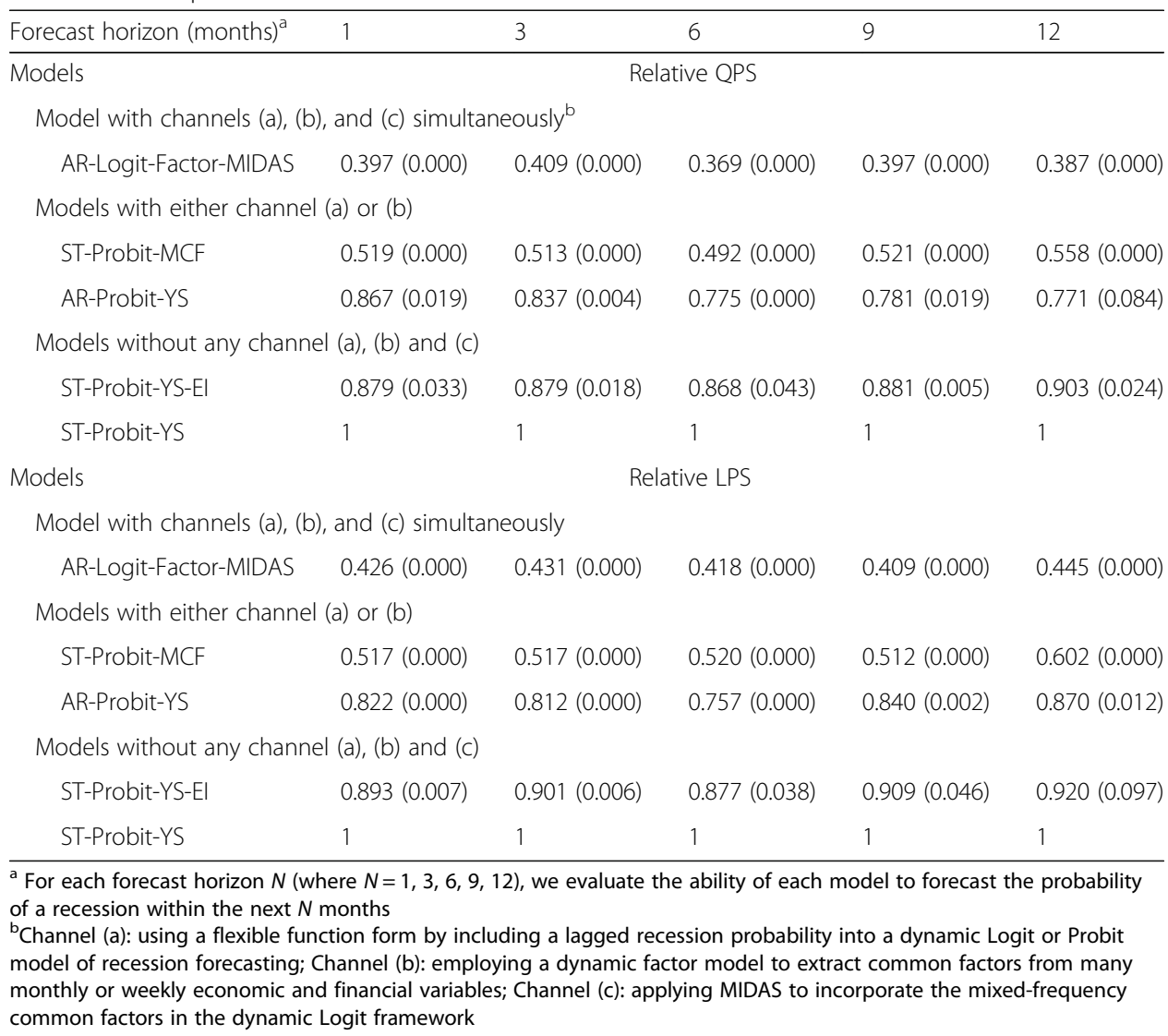

onset of a recession and indicate a weak recession signal (with low predicted probability) shortly after the end of a recession. Figure 2 compares the predicted probability of a recession occurring within the next six months generated by AR-Logit-Factor-MIDA $\mathrm{S}$ with the actual recession periods. For the last three recession periods, the proposed model can predict a strong recession signal one to four months in advance of the onset

Table 2 In-sample estimation results: AUC

\begin{tabular}{|c|c|c|c|c|c|}
\hline Forecast horizon (months) $^{a}$ & 1 & 3 & 6 & 9 & 12 \\
\hline Models & & & AUC & & \\
\hline \multicolumn{6}{|c|}{ Model with channels (a), (b), and (c) simultaneously ${ }^{\mathrm{b}}$} \\
\hline AR-Logit-Factor-MIDAS & $0.980(0.000)$ & $0.980(0.000)$ & $0.980(0.000)$ & $0.981(0.000)$ & $0.981(0.000)$ \\
\hline \multicolumn{6}{|c|}{ Models with either channel (a) or (b) } \\
\hline ST-Probit-MCF & $0.970(0.000)$ & $0.971(0.000)$ & $0.970(0.000)$ & $0.969(0.000)$ & $0.964(0.000)$ \\
\hline AR-Probit-YS & $0.912(0.000)$ & $0.916(0.000)$ & $0.927(0.000)$ & $0.917(0.000)$ & $0.923(0.000)$ \\
\hline \multicolumn{6}{|c|}{ Models without any channel (a), (b) and (c) } \\
\hline ST-Probit-YS-El & $0.890(0.000)$ & $0.888(0.000)$ & $0.900(0.000)$ & $0.897(0.000)$ & $0.912(0.000)$ \\
\hline ST-Probit-YS & $0.863(0.000)$ & $0.864(0.000)$ & $0.868(0.000)$ & $0.871(0.000)$ & $0.893(0.000)$ \\
\hline
\end{tabular}

${ }^{a}$ For each forecast horizon $N$ (where $N=1,3,6,9,12$ ), we evaluate the ability of each model to forecast the probability of a recession within the next $N$ months

${ }^{b}$ Channel (a): using a flexible function form by including a lagged recession probability into a dynamic Logit or Probit model of recession forecasting; Channel (b): employing a dynamic factor model to extract common factors from many monthly or weekly economic and financial variables; Channel (c): applying MIDAS to incorporate the mixed-frequency common factors in the dynamic Logit framework 
of each recession period. The proposed model can also predict an almost-zero recession probability in the month right after the end of each recession period.

We further compare the turning point prediction performance of AR-LogitFactor-MIDAS with that of the alternative models. Figures 3, 4 and 5 illustrate the predicted probability of a recession occurring within the next six months generated by different models for the three most recent recessions. ${ }^{23}$

In predicting the 1990-1991 recession, the performance of AR-Logit-FactorMIDAS surpasses that of AR-Probit-YS, ST-Probit-YS-EI, and ST-Probit-YS, not only in terms of pinpointing the turning points of the business cycle but also in persistently producing high recession probabilities throughout the recession period. Although ST-Probit-MCF also produces high recession probabilities over the entire recession period, it cannot indicate a strong recession signal (i.e., a predicted probability of 0.5 or above) before the start of the recession and its predicted recession probability remains relatively high for three months after the end of the recession. It also produces a false alarm in the third quarter of 1991, when the predicted probability jumps from 0.1 in July 1991 to about 0.3 in August 1991.

For the 2001 recession, AR-Logit-Factor-MIDAS and ST-Probit-YS-EI display similar forecasting performance possibly because this recession was driven by both the bursting of the IT bubble in 2000 and the terrorist attacks on September 11, 2001. Since many IT companies are listed on stock exchanges, the inclusion of the stock market index in ST-Probit-YS-EI may have helped it better predict this recession. The forecasting performance of the other models is unsatisfactory. Both ST-Probit-MCF and ST-Probit-YS predict high recession probabilities only in the later periods of the recessions. Although AR-Probit-YS can issue strong recession signals a few months before the peak of the business cycle, it tends to produce signals indicating that the recession will end soon too early.

Finally, in predicting the recent 2007-2009 recession, AR-Logit-Factor-MIDAS again outperforms AR-Probit-YS, ST-Probit-YS-EI, and ST-Probit-YS for similar reasons to those noted for the 1990-1991 recession. Here, AR-Logit-Factor-MIDAS and STProbit-MCF display similar forecasting performance for the recent recession, although the former tends to have more stable predictive power. The ST-Probit-MCF model predicts a sudden sharp decline in the recession probability in June 2008 and issues a false alarm in late 2009 .

\section{Potential issues in practical applications}

There are some practical issues in implementing our AR-Logit-Factor-MIDAS model. First, unlike most financial variables, data for most macroeconomic variables are not available in real time due to publication lags to varying degrees. To address this issue, we only use variables published within 1 month, that is, at the end of month $t$, variable values applied to months up to $t-1$ are available. This means that in real time (i.e., at the end of month $t$ ), we do not have full data to predict the probability of a recession that falls between $t+1$ and $t+N$. However, we can use the available data up to month $t-1$ to predict the probability of a

\footnotetext{
${ }^{23} \mathrm{We}$ also compare their performance in predicting the turning points for other forecast horizons, that is, $P_{t}\left(Y_{t+N}=1\right)$, where $N=1,3,9,12$, for the three recession periods. The results are similar to those for $N=6$.
} 
Table 3 Out-of-sample estimation results: relative QPS and LPS

\begin{tabular}{|c|c|c|c|c|c|}
\hline$\overline{\text { Forecast horizon (months) }^{\mathrm{a}}}$ & 1 & 3 & 6 & 9 & 12 \\
\hline Models & & & Models & & \\
\hline \multicolumn{6}{|c|}{ Model with channels (a), (b), and (c) simultaneously ${ }^{\mathrm{b}}$} \\
\hline AR-Logit-Factor-MIDAS & $0.485(0.000)$ & $0.528(0.000)$ & $0.489(0.000)$ & $0.696(0.004)$ & $0.664(0.001)$ \\
\hline \multicolumn{6}{|c|}{ Models with either channel (a) or (b) } \\
\hline ST-Probit-MCF & $0.612(0.005)$ & $0.631(0.005)$ & $0.657(0.002)$ & $0.725(0.019)$ & $0.686(0.006)$ \\
\hline AR-Probit-YS & $0.981(0.672)$ & $0.949(0.224)$ & $0.944(0.356)$ & $0.877(0.001)$ & $0.867(0.000)$ \\
\hline \multicolumn{6}{|c|}{ Models without any channel (a), (b) and (c) } \\
\hline ST-Probit-YS-El & $0.889(0.042)$ & $0.889(0.070)$ & $0.962(0.612)$ & $0.912(0.188)$ & $0.933(0.314)$ \\
\hline ST-Probit-YS & 1 & 1 & 1 & 1 & 1 \\
\hline Models & & & tive LPS & & \\
\hline \multicolumn{6}{|c|}{ Model with channels (a), (b), and (c) simultaneously } \\
\hline AR-Logit-Factor-MIDAS & $0.703(0.006)$ & $0.635(0.028)$ & $0.530(0.000)$ & $0.734(0.009)$ & $0.783(0.002)$ \\
\hline \multicolumn{6}{|c|}{ Models with either channel (a) or (b) } \\
\hline ST-Probit-MCF & $0.784(0.341)$ & $0.691(0.044)$ & $0.701(0.012)$ & $0.790(0.130)$ & $0.874(0.509)$ \\
\hline AR-Probit-YS & $0.923(0.051)$ & $0.887(0.000)$ & $0.904(0.036)$ & $0.856(0.000)$ & $0.846(0.000)$ \\
\hline \multicolumn{6}{|c|}{ Models without any channel (a), (b) and (c) } \\
\hline ST-Probit-YS-El & $0.869(0.020)$ & $0.872(0.019)$ & $0.931(0.231)$ & $0.893(0.080)$ & $0.903(0.112)$ \\
\hline ST-Probit-YS & 1 & 1 & 1 & 1 & 1 \\
\hline
\end{tabular}

${ }^{a}$ For each forecast horizon $N$ (where $N=1,3,6,9,12$ ), we evaluate the ability of each model to forecast the probability of a recession within the next $N$ months

${ }^{b}$ Channel (a): using a flexible function form by including a lagged recession probability into a dynamic Logit or Probit model of recession forecasting; Channel (b): employing a dynamic factor model to extract common factors from many monthly or weekly economic and financial variables; Channel (c): applying MIDAS to incorporate the mixed-frequency common factors in the dynamic Logit framework

recession that falls between months $t$ and $t+N-1$. Without the NBER's formal declaration for the actual recession dates (that may take several months before a recession actually starts), a high probability projected for the period between month $t$ and month $t+N-1$, even though month $t$ has already passed, still provides valuable information for economic agents.

Table 4 Out-of-sample estimation results: AUC

\begin{tabular}{|c|c|c|c|c|c|}
\hline Forecast horizon (months) $^{a}$ & 1 & 3 & 6 & 9 & 12 \\
\hline Models & & & AUC & & \\
\hline \multicolumn{6}{|c|}{ Model with channels (a), (b), and (c) simultaneously ${ }^{\mathrm{b}}$} \\
\hline AR-Logit-Factor-MIDAS & $0.913(0.000)$ & $0.937(0.000)$ & $0.953(0.000)$ & $0.925(0.000)$ & $0.927(0.000)$ \\
\hline \multicolumn{6}{|c|}{ Models with either channel (a) or (b) } \\
\hline ST-Probit-MCF & $0.930(0.000)$ & $0.929(0.000)$ & $0.933(0.000)$ & $0.926(0.000)$ & $0.933(0.000)$ \\
\hline AR-Probit-YS & $0.877(0.000)$ & $0.880(0.000)$ & $0.889(0.000)$ & $0.901(0.000)$ & $0.906(0.000)$ \\
\hline \multicolumn{6}{|c|}{ Models without any channel (a), (b) and (c) } \\
\hline ST-Probit-YS-El & $0.910(0.000)$ & $0.893(0.000)$ & $0.889(0.000)$ & $0.901(0.000)$ & $0.897(0.000)$ \\
\hline ST-Probit-YS & $0.857(0.000)$ & $0.842(0.000)$ & $0.876(0.000)$ & $0.864(0.000)$ & $0.866(0.000)$ \\
\hline
\end{tabular}

${ }^{a}$ For each forecast horizon $N$ (where $N=1,3,6,9,12$ ), we evaluate the ability of each model to forecast the probability of a recession within the next $N$ months

${ }^{\mathrm{b}}$ Channel (a): using a flexible function form by including a lagged recession probability into a dynamic Logit or Probit model of recession forecasting; Channel (b): employing a dynamic factor model to extract common factors from many monthly or weekly economic and financial variables; Channel (c): applying MIDAS to incorporate the mixed-frequency common factors in the dynamic Logit framework 
Second, we use final and revised data in our analyses. In practice, however, forecasters often have to rely on initially released data that are subject to subsequent revisions for their model estimation. While a specific variable may be revised up or down in subsequent months, it is unlikely that all the variables are revised in the same direction. It is reasonable to expect that some may be revised up, while others may be revised down. With the large number of explanatory variables used in our model estimation and forecasting, the distortions in different directions due to the data revisions of different variables tend to cancel out each other. Thus, the impact of data revision in our context might be of secondary importance. ${ }^{24}$ Concretely, Bernanke and Boivin (2003) find that the impact of data revisions is insignificant in their vector autoregressive model that uses DFM to extract common factors from a large number of variables. Moreover, Chen et al. (2011) make a similar argument, while Clements (2015) and Fossati (2015) provide further supporting evidence.

Finally, we use the NBER data on the recession dates to construct the dependent variable. Such data are announced by the Business Cycle Dating Committee of the NBER with a substantial time delay ranging from five months (for the recession beginning in January 1980) to 12 months (for the recession starting in December 2007). On average, the announcement delay (or publication lag) was eight months during 1980-2008. The publication lag of recession dates means that we may be unable to obtain a real-time definition of the dependent variable in practice. This implies that the most recent data of the explanatory variables cannot be used for the parameter estimation. To evaluate whether the forecasting performance of our AR-Logit-Factor-MIDAS model is robust to different publication lags, we conduct a robustness check for out-of-sample performance. For a given publication lag of $n$ months $(n=2,3,4,6,12)$, in each moving sample window, we use the data for the dependent and explanatory variables up to time $t-1-n$ to estimate the parameters. Then, we use the estimated parameters and data for the explanatory variables up to time $t$ to forecast $P_{t}\left(Y_{t+6}=1\right)$. The first sample window refers to the period from January 1973 to December 1986 and the last sample window from January 1973 to June 2010. Figure 6 illustrates that for cases with short (2-4 months) and long (6-12 months) publication lags, the proposed model can generate reasonably accurate recession forecasts for the 1990-1991 and 2007-2009 recessions. However, only the model with short publication lags can identify the 2001 recession. The weak predictive power for the model with long publication lags can be largely explained by the fact that economic activities during the period were not particularly weak for a model to identify. ${ }^{25}$ On balance, the publication lag issue does not seem to affect the forecasting performance of our model in a significant way.

\section{Performance of forecasting conventional target variable}

So far, we have found compelling results that the proposed model outperforms other popular models in forecasting the new target variable (a recession will occur at any

\footnotetext{
${ }^{24}$ Data revision may be a more serious issue for models that include only a small set of explanatory variables because with higher chances these variables will be revised in the same direction.

${ }^{25}$ The 2001 recession only lasted for nine months between March and November 2001 and economic activity during this period was mixed: GDP declined in the second quarter but rose in the third quarter and declined again in the fourth quarter, largely due to the unexpected September 11 event. The NBER committee mentioned that it might not have been characterized as a recession without the September 11 event.
} 
time within the next $N$ periods). A natural question is to evaluate whether the proposed model also excels in predicting the conventional target variable (a recession will occur in the $N^{\text {th }}$ period) relative to the other models. This comparison is meaningful given that most popular models in the literature are designed to predict the conventional target variable.

We conduct the same in- and out-of-sample analysis for all the models as in Insample performance and Out-of-sample performance sections. The only difference is the use of the conventional target variable as the dependent variable. Tables 5 and 6 report the in- and out-of-sample estimation results, respectively. The insample results suggest that AR-Logit-Factor-MIDAS has a smaller forecast error (as measured by either the QPS or the LPS) over all the forecast horizons than the other models. The out-of-sample results show that AR-Logit-Factor-MIDAS has a relatively small forecast error over forecast horizons from one to nine months. Interestingly, when the forecast horizon is 12 months, the models that address none of the three channels (ST-Probit-YS-EI and ST-Probit-YS) outperform the other models that address any of the three channels.

In summary, AR-Logit-Factor-MIDAS largely dominates the other models when applied to the conventional target variable, with the exception of the forecast horizon of 12 months. This exception suggests an advantage of using the new target variable.

Table 5 Forecasting the conventional target variable: in-sample estimation results

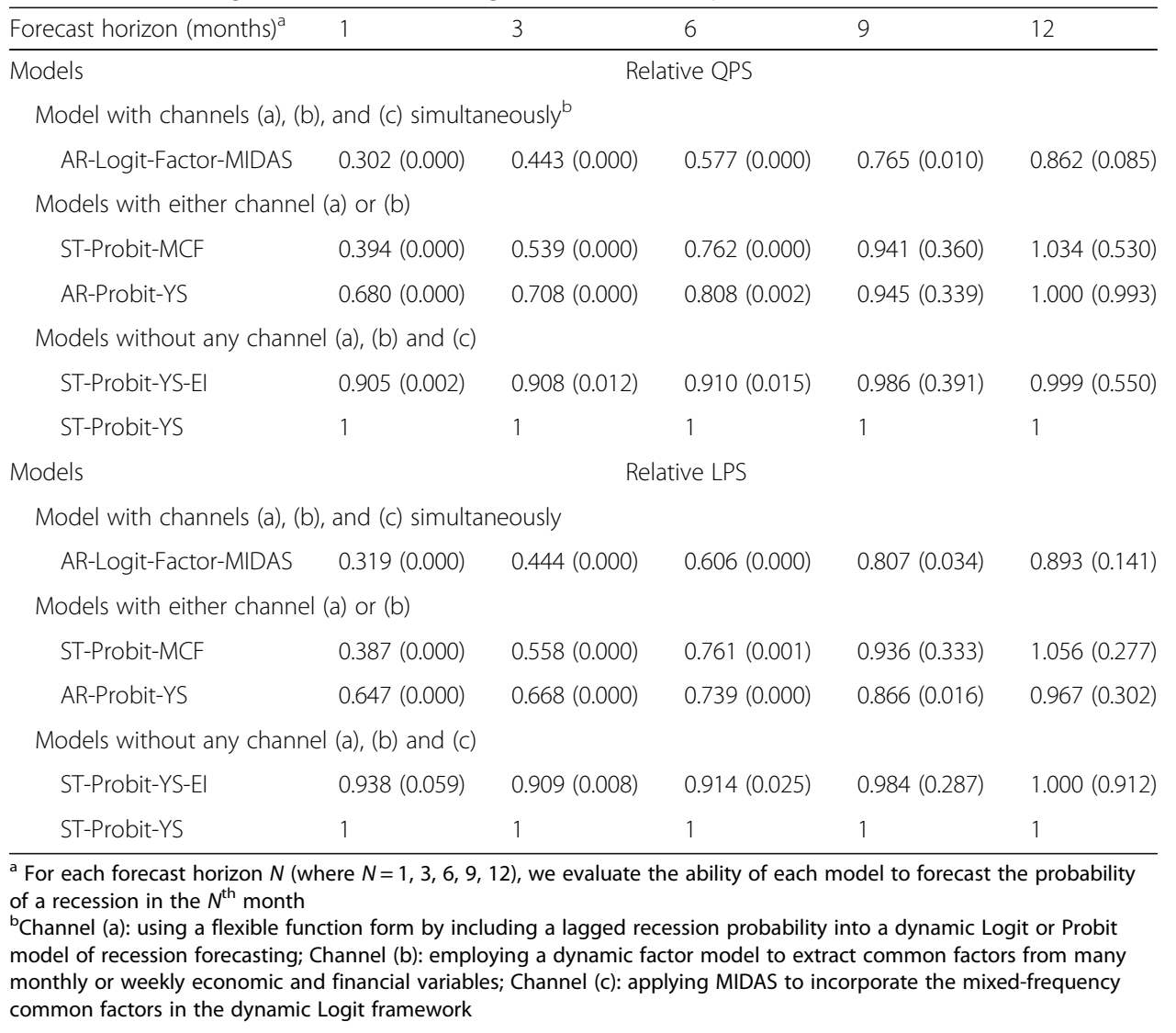


Table 6 Forecasting the conventional target variable: out-of-sample estimation results

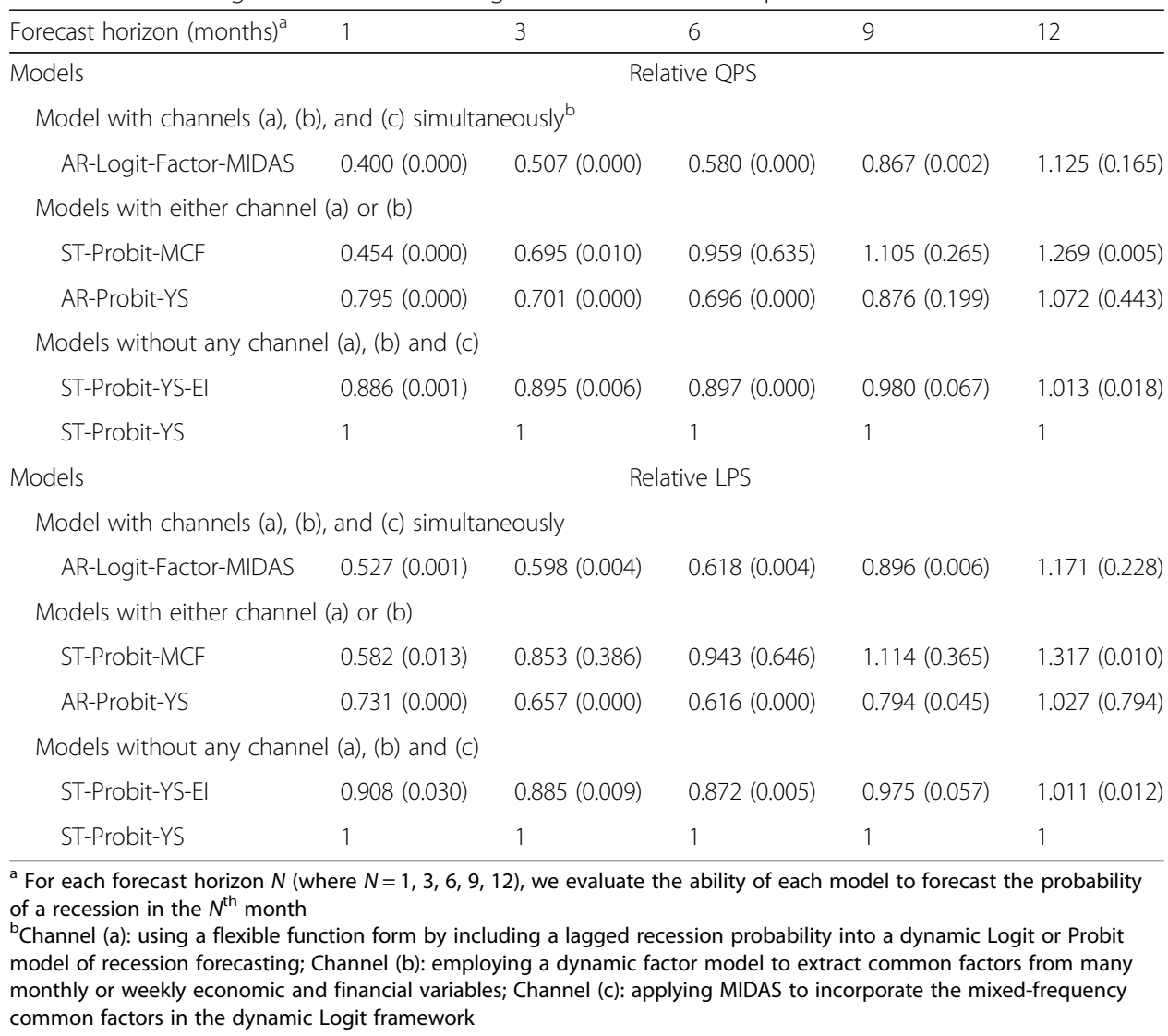

\section{Conclusion}

Accurately forecasting the economic outlook is crucial for practitioners to make timely investment decisions and for policymakers to implement preemptive policies. This study proposes a unified framework that improves the performance of recession modeling and forecasting. It uses a less restrictive target variable and a more flexible and inclusive modeling framework than those used in the literature. Its less restrictive target variable is conceptually more relevant to the decision making of economic agents and can predict an upcoming recession with a high degree of probability. The unified modeling framework captures the autocorrelation of business cycles by using an autoregressive Logit specification, incorporates rich information from many data sources by using a dynamic factor model to extract common factors, and combines the mixed-frequency common factors by applying the MIDAS principle. The model generates significantly more accurate forecasts for U.S. recessions with smaller forecast errors and stronger early signals for the turning points of business cycles than those generated by existing models. We acknowledge the potential issues in implementing our model and explain that these issues may not significantly affect its overall robustness. 
Authors' contributions

Both authors contribute in all aspects of the paper development. Each author may have done more in specific component, but overall they contribute equally to the whole paper. The authors read and approved the final manuscript.

Funding

Lai gratefully acknowledges research funding from School of Accounting and Finance, Faculty of Business, Hong Kong Polytechnic University.

\section{Availability of data and materials}

The original macroeconomic variables used in this study will be available upon request.

\section{Competing interests}

The authors declare that they have no competing interests.

\section{Author details}

15chool of Accounting and Finance, Faculty of Business, Hong Kong Polytechnic University, Hong Kong, China.

${ }^{2}$ Department of Economics, Hong Kong University of Science and Technology, Hong Kong, China.

\section{Received: 3 October 2019 Accepted: 3 July 2020}

Published online: 07 September 2020

\section{References}

Andreou, E., Ghysels, E., \& Kourtellos, A. (2010). Should Macroeconomic Forecasters Look at Daily Financial Data? Journal of Business and Economic Statistics, 31, 240-251

Andreou, E., Ghysels, E., \& Kourtellos, A. (2011). Forecasting with mixed-frequency data. In M. P. Clements, \& D. F. Hendry (Eds.), Oxford handbook of economic forecasting, New York: Oxford University Press. (pp. 225-246).

Bai, J., \& Ng, S. (2006). Confidence intervals for diffusion index forecasts and inference for factor augmented regressions. Econometrica, 74, 1133-1150.

Bai, J., \& Ng, S. (2008). Extremum estimation when the predictors are estimated from large panels. Annals of Economics and Finance, 9, 201-222.

Berg, A., \& Coke, R. N. (2004). Autocorrelation-corrected standard errors in panel Probits: An application to currency crisis prediction. IMF working paper WP/04/39.

Berg, A., \& Pattillo, C. (1999a). Predicting currency crisis: The indicators approach and an alternative. Journal of International Money and Finance, 18(4), 561-586.

Berg, A., \& Pattillo, C. (1999b). What caused the Asian crisis: An early warning system approach. Economic Notes, 28(3), 285334.

Berge, T., \& Jordà, Ò. (2011). Evaluating the classification of economic activity into expansions and recessions. American Economic Journal: Macroeconomics, 3, 246-277.

Bernanke, B. S., \& Boivin, J. (2003). Monetary policy in a data-rich environment. Journal of Monetary Economics, 50, 525-546.

Boivin, J., \& Ng, S. (2005). Understanding and comparing factor-based forecasts. International Journal of Central Banking, 1(3), $117-151$.

Bussiere, M., \& Fratzscher, M. (2002). Towards a new early warning system of financial crises. European Central Bank Working Paper 145 .

Chauvet, M., \& Potter, S. (2005). Forecasting recessions using the yield curve. Journal of Forecasting, 24(2), 77-103.

Chen, Z., Iqbal, A., \& Lai, H. (2011). Forecasting the probability of U.S. recessions: A Probit and dynamic factor modeling approach. Canadian Journal of Economics, 44(2), 651-672.

Christiansen, C., Eriksen, J. N., \& Møller, S. V. (2014). Forecasting US recessions: The role of sentiment. Journal of Banking \& Finance, 49, 459-468.

Clements, M. P. (2015). Real-time factor model forecasting and the effects of instability. Computation Statistics and Data Analysis, 100, 661-675.

Clements, M. P., \& Galvão, A. B. (2008). Macroeconomic forecasting with mixed-frequency data: Forecasting output growth in the United States. Journal of Business and Economic Statistics, 26, 546-554.

Clements, M. P., \& Galvão, A. B. (2009). Forecasting US output growth using leading indicators: An appraisal using MIDAS models. Journal of Applied Econometrics, 24, 1187-1206.

D'Agostino, A., \& Giannone, D. (2012). Comparing alternative predictors based on large-panel dynamic factor models. Oxford Bulletin of Economics and Statistics, 74(2), 306-326

Diebold, F. X. \& Mariano, R. S. (1995). Comparing predictive accuracy. Journal of Business and Economic Statistics, 13, $253-265$.

Dueker, M. (2005). Dynamic forecasts of qualitative variables: A qual VAR model of U.S. recessions. Journal of Business and Economic Statistics, 16, 198-205.

Edison, H. J. (2003). Do indicators of financial crisis work? An evaluation of an early warning system. International Journal of Finance and Economics, 8(1), 11-53.

Estrella, A., \& Mishkin, F. S. (1998). Predicting U.S. recessions: Financial variables as leading indicators. Review of Economics and Statistics, 80, 45-61.

Estrella, A., Rodrigues, A. P., \& Sebastian Schich, S. (2003). How stable is the predictive power of the yield curve? Evidence from Germany and the United States. Review of Economics and Statistics, 85(3), 629-644

Filardo, A. J. (1999). How reliable are recession prediction models. Economic Review, 84(2), 35-55.

Filardo, A. J., 2004. The 2001 US recession: what did the recession prediction models tell us? Bank of International Settlements Working Paper No. 148, The paper can be find at: https://papers.ssrn.com/sol3/papers.cfm?abstract id=699401

Fildes, R., \& Stekler, H. (2002). The state of macroeconomic forecasts. Journal of Macroeconomics, 24, 435-468. 
Forni, M., Hallin, M., Lippi, M., \& Reichlin, L. (2000). The generalized dynamic factor model: Identification and estimation. Review of Economics and Statistics, 82, 540-554.

Forni, M., Hallin, M., Lippi, M., \& Reichlin, L. (2004). The generalized dynamic factor model: Consistency and rates. Journal of Econometrics, 119, 231-255.

Forni, M., Hallin, M., Lippi, M., \& Reichlin, L. (2005). The generalized dynamic factor model: One-sided estimation and forecasting. Journal of the American Statistical Association, 100, 830-840.

Fossati, S. (2015). Forecasting U.S. recessions with macro factors? University of Alberta Working Paper. https://sites.ualberta.ca/ sfossati/files/pdfs/forecasting_nber.pdf.

Fuertes, A.-M., \& Kalotychou, E. (2007). Towards the optimal design of an early warning system for sovereign debt crises. International Journal of Forecasting, 23, 85-100.

Ghysels, E., Santa-Clara, P., \& Valkanov, R. (2004). The MIDAS touch: Mixed data sampling regression models. In CIRANO working papers 2004s-20. Montreal: CIRANO.

Ghysels, E., Santa-Clara, P., \& Valkanov, R. (2005). There is a risk-return tradeoff after all. Journal of Financial Economics, 76, $509-548$.

Ghysels, E., Santa-Clara, P., \& Valkanov, R. (2006). Predicting volatility: Getting the most out of return data sampled at different frequencies. Journal of Econometrics, 131, 59-95.

Ghysels, E., Sinko, A., \& Valkanov, R. (2007). MIDAS regressions: Further results and new directions. Econometric Reviews, 26(1), 53-90.

Ghysels, E., \& Wright, J. (2009). Forecasting professional forecasters. Journal of Business and Economic Statistics, 27(4), 504-516.

Hanley, J. A., \& McNeil, B. J. (1982). The meaning and use of the area under a receiver operating characteristic (ROC) curve. Radiology, 143(1), 29-36.

Hao, L., \& Ng, E. C. Y. (2011). Predicting Canadian recessions using dynamic Probit modeling approaches. Canadian Journal of Economics, 44(4), 1297-1330.

Hendry, D. F., \& Mizon, G. E. (1978). Serial correlation as a convenient simplification, not a nuisance: A comment on a study of the demand for money by the Bank of England. Economic Journal, 88, 549-563.

Kaminsky, G. L., \& Reinhart, C. M. (1999). The twin crisis: The causes of banking and balance-of-payments problems. American Economic Review, 89(3), 473-500.

Kauppi, H., \& Saikkonen, P. (2008). Predicting U.S. recessions with dynamic binary response models. Review of Economics and Statistics, 90(4), 777-791.

Krane, S. (2003). An evaluation of real GDP forecasts: 1996-2001. Economic Perspectives_Federal Reserve Bank of Chicago, 1Q, 2-21.

Lahiri, K., \& Yang, L. (2013). Forecasting binary outcomes. In G. Elliott, \& A. Timmermann (Eds.), Handbook of forecasting, (vol. 2, pp. 1025-1106). Amsterdam: North-Holland.

Ludvigson, S. C., \& Ng, S. (2009). Macro factors in bond risk premia. Review of Financial Studies, 22(12), 5027-5067.

Ng, E. C. Y. (2012). Forecasting U.S. recessions with various risk factors and dynamic Probit models. Journal of Macroeconomics, 34(1), 112-125.

Ng, S. (2014). Viewpoint: Boosting recessions. Canadian Journal of Economics, 47(1), 1-34.

$\mathrm{Ng}, \mathrm{S} ., \&$ Wright, J. (2013). Facts and challenges from the great recession for forecasting and macroeconomic modeling. Journal of Economic Literature, 51(4), 1120-1154.

Nyberg, H. (2010). Dynamic Probit models and financial variables in recession forecasting. Journal of Forecasting, 29(1-2), 215-230.

Rudebusch, G., \& Williams, J. (2009). Forecasting recessions: The puzzle of the enduring power of the yield curve. Journal of Business and Economic Statistics, 27, 492-503.

Rydberg, T. H., \& Shephard, N. (2003). Dynamics of trade-by-trade price movements: Decomposition and models. Journal of Financial Econometrics, 1, 2-25.

Stock, J. H., \& Watson, M. W. (1999). Forecasting inflation. Journal of Monetary Economics, 44(2), 293-335.

Stock, J. H., \& Watson, M. W. (2002a). Forecasting using principal components from a large number of predictors. Journal of the American Statistical Association, 97, 1167-1179.

Stock, J. H., \& Watson, M. W. (2002b). Macroeconomic forecasting using diffusion indexes. Journal of Business and Economic Statistics, 20, 147-162.

Stock, J. H., \& Watson, M. W. (2003). How did leading indicator forecasts do during the 2001 recession? Economic Quarterly_Federal Reserve Bank of Richmond, 89(3), 71-90.

Stock, J. H., \& Watson, M. W. (2011). Dynamic factor models. In M. P. Clements, \& D. F. Hendry (Eds.), Oxford handbook of economic forecasting, (pp. 35-59). New York: Oxford University Press.

Wright, J. (2006). The yield curve and predicting recessions. Finance and economics discussion series. Federal Reserve Board, February. https:/www.federalreserve.gov/pubs/feds/2006/200607/200607pap.pdf.

\section{Publisher's Note}

Springer Nature remains neutral with regard to jurisdictional claims in published maps and institutional affiliations. 